Check for updates

Cite this: J. Anal. At. Spectrom., 2017, 32, 1848

Received 28th July 2017

Accepted 29th August 2017

DOI: 10.1039/c7ja00260b

rsc.li/jaas

\section{Recent advances in the analysis of non-traditional stable isotopes by multi-collector inductively coupled plasma mass spectrometry}

\author{
Dawei Lu, ${ }^{\text {ab }}$ Tuoya Zhang, ${ }^{\text {ab }}$ Xuezhi Yang, ${ }^{a}$ Peng Su, ${ }^{\text {ab }}$ Qian Liu (DD *abc \\ and Guibin Jiang ${ }^{\text {ab }}$
}

\begin{abstract}
Non-traditional stable isotopes, with no clear definition yet, generally refer to isotopes beyond $\mathrm{C}, \mathrm{H}, \mathrm{O}, \mathrm{N}$, and $\mathrm{S}$ with small variations in natural stable isotopic compositions, such as isotopes of transition and heavy metal elements. With the rapid development in the multi-collector inductively coupled plasma mass spectrometry (MC-ICP-MS) technique, non-traditional stable isotopes have emerged as powerful tracers in geosciences, archaeology, anthropology, and environmental sciences. This article summarizes the recent advances in the analysis of non-traditional stable isotopes by MC-ICP-MS. We review recent efforts on improvement of the sensitivity of MC-ICP-MS and optimization of the sample preparation procedures. Special attention is paid to the "emerging" stable isotopes, e.g., vanadium $(\mathrm{V})$, barium $(\mathrm{Ba})$, potassium $(\mathrm{K})$, platinum (Pt), palladium $(\mathrm{Pd})$, silver (Ag), cerium (Ce), erbium (Er), and silicon (Si). We also introduce some novel aspects of the application of non-traditional stable isotopes, e.g., in nanotechnology and environmental health studies. Finally, we discuss current challenges and give our perspectives in this active research area.
\end{abstract}

\section{Introduction}

Isotopes are atoms with the same number of protons and different number of neutrons in their nuclei. ${ }^{1}$ Isotopes include

${ }^{a}$ State Key Laboratory of Environmental Chemistry and Ecotoxicology, Research Center for Eco-Environmental Sciences, Chinese Academy of Sciences, 18 Shuangqing Road, Haidian District, Beijing 100085, China. E-mail: qianliu@rcees.ac.cn; Fax: +86-10-62849339 ${ }^{b}$ University of Chinese Academy of Sciences, Beijing 100190, China

${ }^{c}$ Institute of Environment and Health, Jianghan University, Wuhan 430056, China

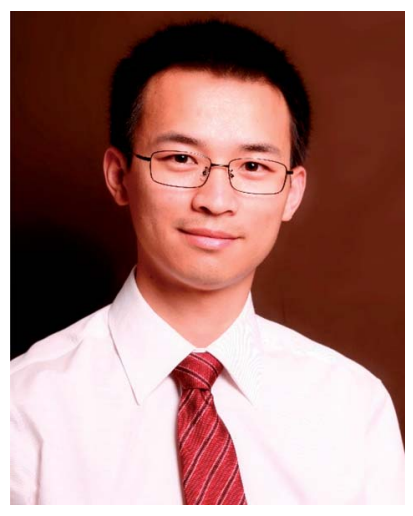

Dr Qian Liu is a Professor at Research Center for EcoEnvironmental Sciences, Chinese Academy of Sciences. He obtained his Ph.D. in analytical chemistry from Hunan University in 2009. He has won the China National Science Fund for Excellent Young Scholars, the Chinese Society for Environmental Sciences Award for Young Scientist, and the Chinese Chemical Society Award for Outstanding Young Chemist. His current research interests include (i) development of new analytical methods for trace levels of pollutants, (ii) use of stable isotopes to study the processes and trace the sources of pollutants, and (iii) environmental nanotechnology. radioactive and stable isotopes. Stable isotope fractionation describes the phenomenon that the stable isotopic composition of an element changes during the partitioning of isotopes between two substances or two phases due to the isotope effect. ${ }^{1}$ Stable isotope fractionation can occur during different geochemical, environmental, and biological processes to cause variations in stable isotope ratios. ${ }^{2}$ Stable isotope fractionation can be used as a novel tool to trace the sources and study the transport process of elements in environmental and biological systems. ${ }^{3-10}$ In the past few decades, "traditional" stable isotopes, e.g., $\mathrm{C}, \mathrm{H}, \mathrm{O}, \mathrm{N}$, and $\mathrm{S}$, have greatly broadened our insights into the biogeochemical cycles of these elements. ${ }^{\mathbf{1 1 , 1 2}}$ However, for isotopes beyond the traditional isotopes, such as those of transition elements and heavy metal elements, their analytical instruments and methodology are still deficient, which seriously limits their research and application. These isotopes are often called "non-traditional" stable isotopes.

To date, measurement of non-traditional stable isotopic compositions mainly depends on three types of mass spectrometry (MS) techniques: gas source mass spectrometry, thermal-ionization mass spectrometry (TIMS), and multicollector inductively coupled plasma mass spectrometry (MC-ICP-MS). ${ }^{13}$ These techniques have similar analyzer parts but different sample introduction and ionization systems. Specifically, gas source mass spectrometry is normally used to determine the stable isotope ratios of halogens, because halogens can easily be transformed into the gaseous state. ${ }^{\mathbf{1 4 , 1 5}}$ TIMS can provide an ion beam of $\sim 0.5 \mathrm{eV}$ and it is suitable to analyze elements with ionization potentials less than $7.5 \mathrm{eV}$, such as 
alkali metals and rare earth metals. ${ }^{16} \mathrm{MC}-\mathrm{ICP}-\mathrm{MS}$ is a relatively new technique. It was first reported by Walder et al. for the analysis of stable isotope ratios in $1993 .{ }^{17}$ The MC-ICP-MS instrument consists of a sample introduction system, an inductively coupled Ar plasma, an ion transfer system, and multiple mass analyzers. Compared with the other two MS techniques, MC-ICP-MS has outstanding advantages such as highly efficient ionization, high mass resolution, and high sample throughput. ${ }^{\mathbf{1 1 , 1 8 , 1 9}}$ Therefore, it has gained rapid development in stable isotopic analysis of various elements in the last two decades. ${ }^{\mathbf{1 8 , 2 0 - 2 4}}$ Nevertheless, many challenges remain in the development of MC-ICP-MS methods, including the instrumental mass bias, sample matrix effect, and laborious and time-consuming sample purification steps required for the analysis. Several reviews have been published that introduced the fundamentals and principles of the isotopic analysis by MC-ICP-MS, including general rules for mass bias correction and covering different elements (e.g., magnesium $(\mathrm{Mg})$, calcium $(\mathrm{Ca})$, titanium (Ti), chromium (Cr), iron (Fe), nickel (Ni), copper $(\mathrm{Cu})$, zinc $(\mathrm{Zn})$, germanium $(\mathrm{Ge})$, selenium (Se), rubidium ( $\mathrm{Rb})$, strontium ( $\mathrm{Sr}$ ), zirconium $(\mathrm{Zr})$, molybdenum (Mo), ruthenium ( $\mathrm{Ru})$, cadmium (Cd), stannum ( $\mathrm{Sn}$ ), antimony (Sb), tellurium (Te), xenon (Xe), hafnium (Hf), tungsten (W), rhenium (Re), osmium (Os), neodymium (Nd), samarium (Sm), europium (Eu), gadolinium (Gd), dysprosium (Dy), ytterbium (Yb), mercury $(\mathrm{Hg})$, thallium $(\mathrm{Tl})$, lead $(\mathrm{Pb})$, thorium ( $\mathrm{Th})$, radium $(\mathrm{Ra})$, uranium $(\mathrm{U})$, and plutonium $(\mathrm{Pu}))^{11,12,18,19,25-30}$ We notice that in recent years this field continued to undergo rapid development, especially in the following aspects:

(1) More efforts were made to improve the sensitivity and precision of the MC-ICP-MS methods. The newly developed sample pretreatment methods greatly enhanced the analytical capability of MC-ICP-MS for complex samples;

(2) More isotopes (e.g., V, Ba, K, Pt, Pd, Ag, Er, Ce, Si, etc.) can be well analyzed by MC-ICP-MS. These isotopes lacked practical methods to be analyzed in the past, or only little research attention was paid to their analysis. The recent advances in MC-ICP-MS enable accurate and precise measurement of these stable isotopes to satisfy the demands of real applications;

(3) The application of non-traditional stable isotopes was expanded to more research areas due to the improvement in the analytical capability.

Here, we review the recent progress in the development of analytical methods for non-traditional stable isotopes by using MC-ICP-MS as well as their novel applications. Considering that many non-traditional stable isotopes have been well summarized in some recent reviews, ${ }^{\mathbf{1 1 , 1 2 , 1 8 , 1 9 , 2 5 - 3 0}}$ here we pay special attention to the "emerging" stable isotopes (e.g., V, Ba, K, Pt, Pd, $\mathrm{Ag}, \mathrm{Er}, \mathrm{Ce}$, and $\mathrm{Si}$ ) that have gained significant progress in recent years but attracted only little research attention in previous reviews. Notably, we discuss some emerging application fields of stable isotopes, such as in nanotechnology and environmental health science. Finally, we discuss the current challenges remaining in this area and give our future perspectives.

\section{Fundamentals of stable isotope analysis by MC-ICP-MS}

Prior to discussing the analytical methods and applications of non-traditional stable isotopes, it is necessary to introduce some common knowledge on isotopic analysis. Since the fundamentals and principles of isotopic analysis by MC-ICP-MS have been described in detail in some previous reviews, ${ }^{\mathbf{1 1 , 1 8 , 2 7}}$ herein we only give a brief introduction on this aspect. Isotopic compositions are often reported with a relative value referring to an isotopic standard reference material (SRM), whose isotope ratios have been calibrated by multiple laboratories. The isotopic composition of the sample can be described as delta values $(\delta)$ compared to the SRM: ${ }^{12}$

$$
\delta^{x} E=\left(\frac{\left({ }^{x} E /{ }^{y} E\right)_{\text {sample }}}{\left({ }^{x} E /{ }^{y} E\right)_{\text {standard }}}-1\right) \times 1000
$$

where $E$ is a representative element, and $x$ and $y$ represent the mass number of two isotopes of the element.

The variation in the $\delta$ values is used to evaluate the degree of isotope fractionation. The isotope fractionation can be caused by isotope exchange reactions or kinetic processes. ${ }^{1}$ The isotope fractionation can be divided into three types: thermodynamic equilibrium fractionation, kinetic disequilibrium fractionation, and mass-independent isotope fractionation (MIF). In most chemical processes, isotope fractionation arises from isotopic mass variations, that is, mass-dependent isotope fractionation (MDF), whereas, in particular situations, especially in some isotope exchange reactions in the natural environment, the isotope fractionation cannot be described by the mass-dependent fractionation rules. ${ }^{1,31,32}$ In that case, the isotope fractionation is termed MIF. MIF was first found for some light elements (e.g., O and S) in the 1980s and used in the studies of the solar system origin, chemistry and transport of aerosols and so on. ${ }^{32-34}$ In 2007, Bergquist and Blum reported the MIF of $\mathrm{Hg}$, which reveals a unique way to trace the origin and study the environmental behaviors of $\mathrm{Hg} .{ }^{35}$ Since then, the MIF of non-traditional stable isotopes caught much research interest. ${ }^{36-39}$ However, compared with MDF that has been well understood, ${ }^{40}$ the mechanisms of the MIF are still to be explored., ${ }^{1,32,41}$ Vanhaecke et al. have discussed the possible causes of the MIF of non-traditional stable isotopes, including the different nuclear volume effects and magnetic isotope effects. ${ }^{11,13,22,31}$ The MIF can be described by the following equation:

$$
\Delta^{x} E=\delta^{x} E-\lambda \delta^{z} E
$$

where $\Delta$ reflects the difference between the mass-dependent fractionation and mass-independent fractionation, ${ }^{\mathbf{4 2}} \delta$ represents an isotopic composition compared to the standard materials, $E$ is a representative element, and $x$ and $z$ represent the mass number of two isotopes of an element. The coefficient $\lambda$ is a theoretical value, which depends on the molecular mass. The $\lambda$ is an important coefficient to describe the mass dependent fractionation.

Mass bias correction is a critical part in MC-ICP-MS analysis of isotope ratios. The mass bias is related to the preferential 
extraction and transmission of heavier ions in the MS instrument, which will cause a bias between the measured isotope ratio and the true isotope ratio. Although the cause of mass bias in MCICP-MS is not fully understood, it is often ascribed to the "spacecharge effects". ${ }^{43,44}$ The commonly used mass bias correction strategies can be classified into three categories: double (or triple) spike techniques, ${ }^{45,46}$ internal standardization, ${ }^{47,48}$ and external standard-sample bracketing (SSB) technique. ${ }^{49,50}$ The double spike techniques, initially developed for the $\mathrm{Pb}$ isotope measurement with TIMS and currently also applied to other isotope systems with MC-ICP-MS, are based on the analysis of an unspiked sample and a spiked sample, in which two enriched isotopes are added. The isotopic composition of the spike solution must be known. Comparison of the analytical results of the unspiked sample with the spiked sample can obtain the mass bias-corrected isotopic composition of the target elements. The most prominent advantage of the double spike method is its high accuracy because the mass bias correction factor can be easily obtained for each sample. Nevertheless, the double spike technique also has distinct disadvantages, such as the requirement of at least four isotopes for the target elements, the high cost of high-purity enriched isotope materials, the intensive effort required for accurate calibration of the spike composition, and the need of duplicate runs for each sample analysis.

Internal standardization refers to the method that uses a pair of isotopes with constant ratios to correct the mass bias of the target elements. This pair of isotopes (i.e., the internal standard) can be the same element as the target isotopes or other elements. The most popular manner is to add a pair of isotopes of an adjacent element to the sample. The mass bias correction is conducted based on the Russell exponential fractionation law:

$$
R_{\mathrm{M}}=R_{\mathrm{T}} \times\left(\frac{m_{\mathrm{i}}}{m_{\mathrm{j}}}\right)^{f}
$$

where $R_{\mathrm{M}}$ and $R_{\mathrm{T}}$ are the measured and corrected ratios, respectively; $m_{\mathrm{i}}$ and $m_{\mathrm{j}}$ are the absolute masses of the isotopes of interest; $f$ is the mass bias correction factor.

The SSB method is widely used for mass bias correction in isotope ratio analysis due to its simplicity. It is often used together with the internal standardization to ensure high accuracy and precision. ${ }^{51}$ The analytical sequence consists of the sample and the standards that bracket the sample. The correction factor is determined by the bracketing standards and then is used to correct the mass bias in the sample. There are some prerequisites to properly conduct the SSB. The concentration of the target element in the sample and the standards must be at the same level, and the sample needs to be thoroughly purified before analysis to minimize the interference caused by the mismatch of the sample matrix.

\section{Recent efforts on the improvement of analytical performance of MC-ICP- MS}

The current challenges in the MC-ICP-MS measurement of nontraditional stable isotopes in complex samples (e.g., geological and environmental samples) lie mainly in the insufficient sensitivity, matrix effects, determination of species-specific isotopes, and complicated operation steps. Therefore, to improve the analytical performance of MC-ICP-MS, great efforts were made in the modification of mass spectrometer detectors, improvement of sample introduction systems, development of on-line coupling chromatographic systems, and establishment of off-line sample preparation methods.

\subsection{Modification of mass spectrometer detectors}

Appropriate sensitivity is a prerequisite for highly accurate and precise determination of stable isotope ratios by MC-ICP-MS. ${ }^{26}$ For non-traditional stable isotopic analysis in real environmental, biological, geochemical, and medical samples, the element concentrations without pre-concentration are usually too low to meet the detection limits required by MC-ICP-MS. Hence, sensitivity enhancement is critical for non-traditional isotope ratio analysis to push forward its application to more research areas. The modification of mass spectrometer detectors is a helpful approach to improve the sensitivity of some isotopes. For example, Nielsen et al. changed the $10^{11} \Omega$ resistors of the Faraday cups to $10^{12} \Omega$ resistors, which enhanced the signals of ${ }^{50} \mathrm{~V}$ with very low isotope abundance in the measurement of $\mathrm{V}$ isotope ratios. ${ }^{52,53}$ Peters et al. also used $10^{12}$ $\Omega$ resistors with MC-ICP-MS to achieve highly accurate and precise analysis of ${ }^{190} \mathrm{Pt}^{54}$

\subsection{Sample introduction systems}

Regarding the sensitivity enhancement in MC-ICP-MS, the development of "dry-mode" sample introduction systems must be mentioned. There are two frequently used dry-mode sample introduction systems: the Desolvation Nebulizer System developed by $\mathrm{Nu}$ Instruments (Wrexham, UK) and the Apex HF introduction system developed by Elemental Scientific Inc. (Warrington, UK). These inventions significantly improved the analytical sensitivities of non-traditional stable isotopes by MC-ICP-MS. ${ }^{55-57}$ Under the dry mode, the liquid sample was first passed through a heating device $(393-413 \mathrm{~K})$ to remove the solvent from the sample, and then the sample aerosol stream was introduced into the plasma with the sample ionization efficiency being significantly enhanced.

A continuous flow cold-vapor generation (CCVG) system was established to transform $\mathrm{Hg}^{2+}$ into gaseous $\mathrm{Hg}^{0}$ and enabled the direct measurement of the $\mathrm{Hg}$ isotopic composition at the $\mathrm{Hg}$ concentration low to $1 \mu \mathrm{g} \mathrm{L}{ }^{-1} .^{58}$ Donard et al. coupled the cold vapor generation (CVG) and dual gold amalgamation (DGA) to MC-ICP-MS (CVG-DGA-MC-ICP-MS) and applied this method to determine the $\mathrm{Hg}$ isotopic composition at a level of $\mathrm{ng} \mathrm{\textrm {L } ^ { - 1 }}$ in environmental samples. ${ }^{59}$ This method, as depicted in Fig. 1, enabled fully automated and on-line analysis of $\mathrm{Hg}$ isotope ratios. A time-resolved analysis (TRA) mode was adopted to acquire signals and a linear regression slope method was used to calculate the isotope ratios. The precision of this method was $0.26 \%$ o (2SD) for $\delta^{202} \mathrm{Hg}$ and $0.15 \%$ o (2SD) for $\Delta^{199} \mathrm{Hg}$ at a $\mathrm{Hg}$ concentration of $5 \mathrm{ng} \mathrm{L}^{-1}$, near to the real concentration of $\mathrm{Hg}$ in environmental water and atmospheric samples. ${ }^{\mathbf{6 0 , 6 1}}$ 


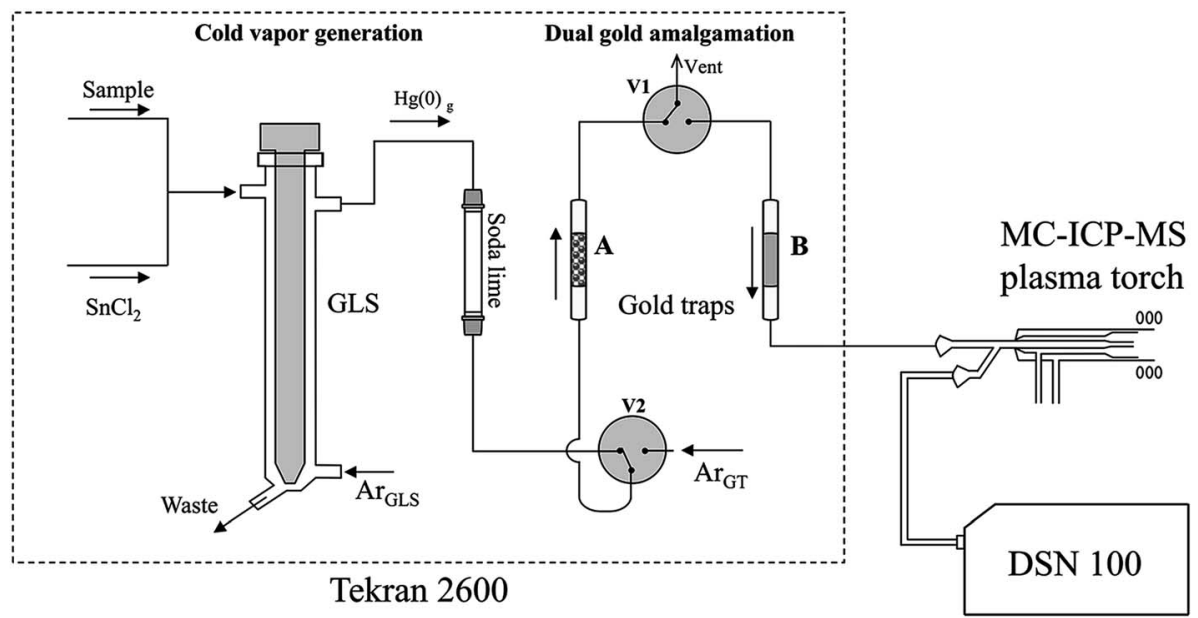

Fig. 1 Illustration of the CVG-DGA/MC-ICP-MS on-line coupling system. GLS is the gas liquid separator, A is the gold sand filled trap, B is the pure gold trap, and V1 and V2 are two electronic valves. ${ }^{86}$ Reproduced by permission of the Royal Society of Chemistry (2017).

\subsection{On-line coupling chromatographic systems to MC-ICP- MS}

To further simplify operation procedures and shorten the analytical time, great efforts have also been made to develop online purification systems coupled to MC-ICP-MS, including ion exclusion chromatography (IEC-MC-ICP-MS), ${ }^{62}$ gas chromatography (GC-MC-ICP-MS), ${ }^{63}$ continuous flow cold-vapor generation system (CCVG-MC-ICP-MS), ${ }^{64,65}$ and laser ablation system (LA-MC-ICP-MS). ${ }^{66-70}$ For example, ${ }^{204} \mathrm{Hg}$ would cause isobaric interference to ${ }^{204} \mathrm{~Pb}$, which makes it difficult to measure $\mathrm{Pb}$ isotope ratios in Hg-rich sulfides. Zhang et al. developed a method for coupling a gas exchange device to LA-MC-ICP-MS (see Fig. 2) for in situ $\mathrm{Pb}$ isotopic analysis in Hg-rich sulfides. ${ }^{71}$ The gas exchange device can completely remove the $\mathrm{Hg}$ vapor from the targeted aerosol particles and bring no influence on the signal intensities of $\mathrm{Pb}$ isotope measurement. On-line separation hyphenation techniques are especially useful for element cycles and the environmental health studies. Because different species of elements have distinctly different physicochemical properties, the on-line separation techniques coupled to MC-ICP-MS can separate different species and enable the rapid determination of isotopic compositions of different species. To date, the GC-MC-ICP-MS has been applied to the species-specific isotopic analysis of $\mathrm{Cl}^{72} \mathrm{Br}^{73} \mathrm{~S}^{74}$ and $\mathrm{Hg} .{ }^{75}$ However, the on-line hyphenation techniques with MC-ICP-MS are still at their infant stage, and they often suffer from the nonquantitative recoveries in the purification processes or unintentional species degradation in the analytical procedures that may cause artificial isotope fractionation. ${ }^{76}$ Therefore, further development and validation are highly desired for the on-line purification methods with MC-ICP-MS.

\subsection{Off-line sample preparation methods for MC-ICP-MS}

Although on-line separation techniques coupled to MC-ICP-MS seem to be a trend in the analytical method development, ${ }^{62-70}$ the off-line sample preparation methods still play predominant roles in the isotopic analysis, because they are still the most reliable way to maintain quantitative recoveries of the target elements and ensure their efficient separation from interference.

For sample pre-concentration, a number of strategies, such as evaporation, ${ }^{77}$ chromatographic enrichment, ${ }^{61}$ trapping, and co-precipitation, ${ }^{20}$ have been used to enrich the trace amount of target elements from various types of samples. Taking $\mathrm{Si}$ as an example, the co-precipitation with $\mathrm{NaOH}$ or $\mathrm{NH}_{3} \cdot \mathrm{H}_{2} \mathrm{O}$ was adopted to enrich the low content of $\mathrm{Si}$ in water samples. To

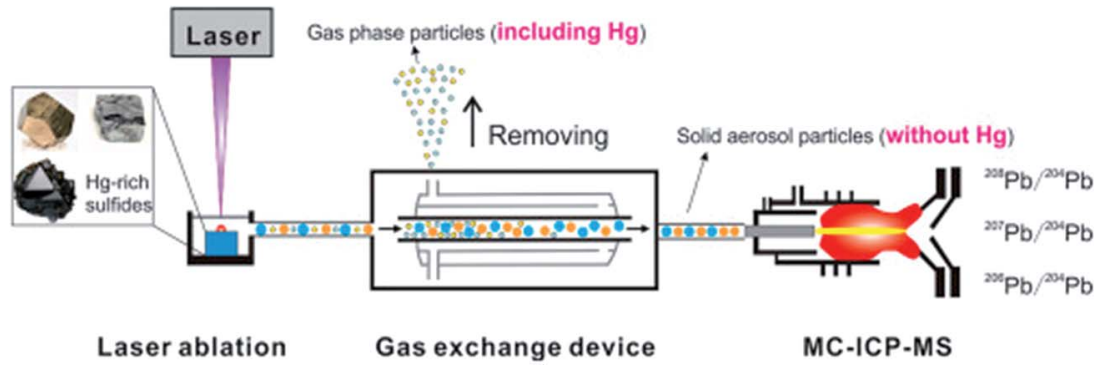

Fig. 2 Schematic representation showing the coupling of laser ablation (LA) with gas exchange device and MC-ICP-MS reported by Zhang et al. ${ }^{71}$ Reproduced by permission of Elsevier (2016). 


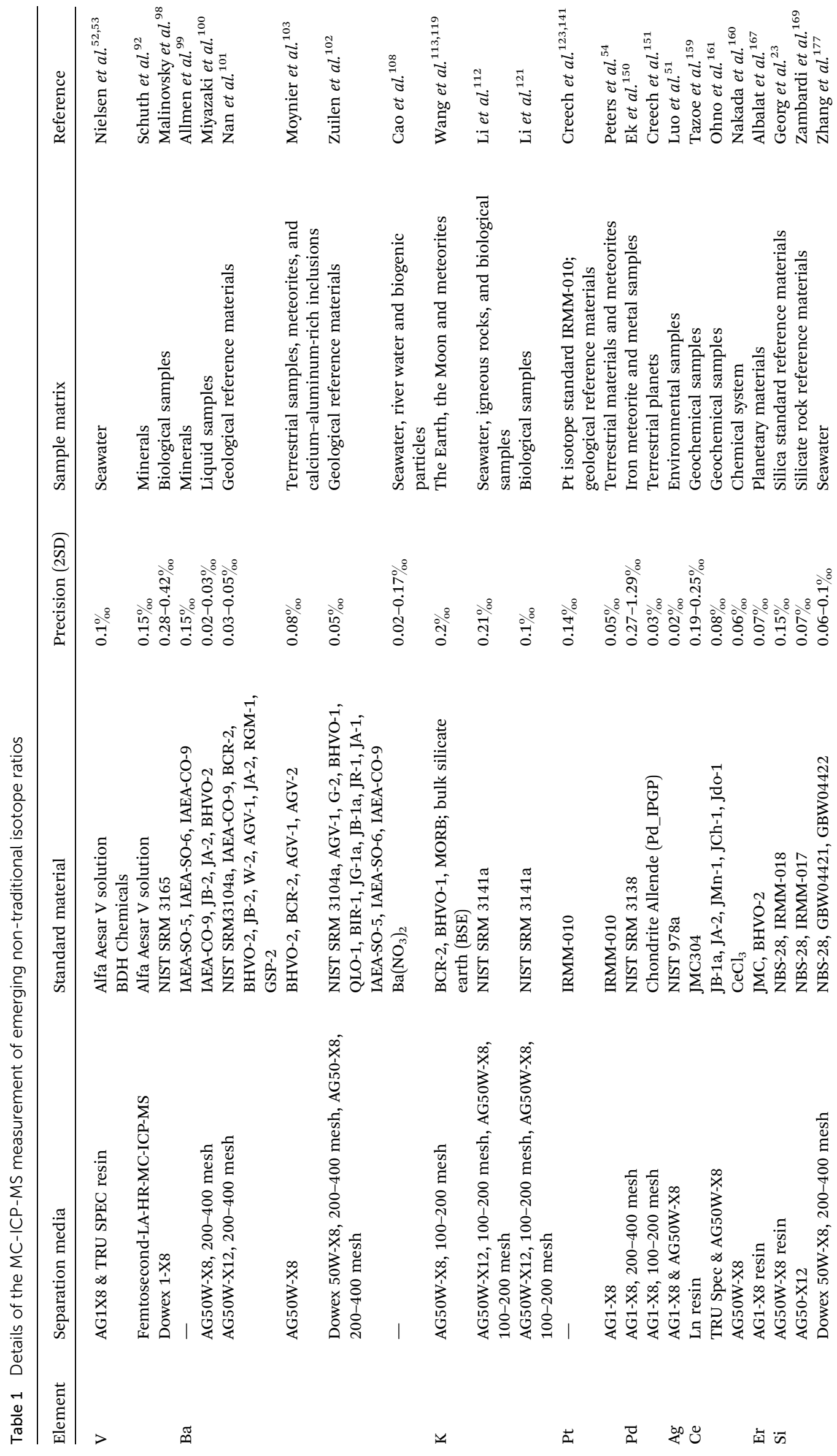


analyze trace $\mathrm{Hg}$, Chen et al. developed a chromatographic method to pre-enrich $\mathrm{Hg}$ from diluted aqueous solutions prior to MC-ICP-MS measurement. ${ }^{61}$ Different trapping methods were also adopted prior to the isotopic analysis with MC-ICP-MS, such as gold trapping, ${ }^{78} \mathrm{KMnO}_{4}$ trapping and acidic solution trapping. ${ }^{79-83}$

In addition, sample matrix can cause serious isobaric interference to the MC-ICP-MS measurement. In previous studies, the same sample matrix was added to standard solutions, and then the matrix effect could be evaluated and subtracted. ${ }^{\mathbf{8 4}}$ Recent studies focused on the removal of sample matrices from target analytes with various ion-exchange column methods. Yang et al. have summarized commonly used separation procedures for 44 elements in $2009 .{ }^{18}$ Here, we list the column purification materials used in the analysis of the emerging isotopes (e.g. V, Ba, K, Pt, Pd, Ag, Er, Ce, and Si) in Table 1. In column purification methods, particular attention should be paid to ensure that no possible fractionation of the target isotopes occurs during the column purification process. For example, Russell et al. found that the lighter isotopes of $\mathrm{Ca}$ could be adsorbed to resin more easily during the column purification process than the heavier ones, and this could cause a Ca isotope fractionation up to $3 \%$ when the Ca was not fully recovered. ${ }^{85}$

\section{Measurement of emerging stable isotope ratios by MC-ICP-MS}

The development of MC-ICP-MS enables accurate and precise determination of a large number of isotopes. ${ }^{13,22}$ Some previous reviews have been published on the analytical method development and applications of non-traditional stable isotopes. ${ }^{11,18,19,25-29}$ Blum et al. have recently published a review paper summarizing the progress in $\mathrm{Hg}$ isotopic analysis. ${ }^{86}$ So herein we only discuss the analytical methods and applications for several representative emerging isotopes, e.g., V, Ba, K, Pt, $\mathrm{Pd}, \mathrm{Ag}, \mathrm{Er}, \mathrm{Ce}$ and $\mathrm{Si}$, which have gained significant advances in recent years but have attracted only little attention in the previous reviews. The recent advances in isotope ratio analysis by MC-ICP-MS greatly facilitated the application of these stable isotope systems in various fields.

\subsection{Vanadium}

$\mathrm{V}$ is an important transition metal element in geochemical studies with four valence states $(+2,+3,+4$, and +5$)$ and two naturally occurring stable isotopes $\left({ }^{50} \mathrm{~V}\right.$ and ${ }^{51} \mathrm{~V}$ with a ratio of 0.24\%: 99.76\%). ${ }^{87}$ The previous studies on $\mathrm{V}$ stable isotopes were limited by the poor precision with TIMS $(>1 \%),{ }^{88,89}$ which was unable to detect potential $\mathrm{V}$ isotope fractionation occurred in the natural environment. The high accuracy and precision determination of V stable isotopes by MC-ICP-MS was reported in recent years by Nielsen et al., Prytulak et al., and $\mathrm{Wu}$ et al., with a precision of $0.1 \%$ (2SD). ${ }^{52,90,91}$ Schuth et al. reported the in situ $\mathrm{V}$ isotope analysis in mineral samples using a femtosecond-laser ablation-high resolution-MC-ICP-MS (fs-LA-MCICP-MS). Compared with the solution-nebulizer sample introduction method, the precision of the in situ fs-LA-MC-ICPMS method was at the same level (2SD $0.15 \%$ ). ${ }^{92}$

For the measurement of $\mathrm{V}$ isotope ratios with MC-ICP-MS, only two natural $\mathrm{V}$ isotopes limit the use of the double spike method for mass bias correction. Thus, only the external normalization with the SSB technique could be adopted. Chromatographic separation methods were used to separate the $\mathrm{V}$ element from the complex sample matrix with a high extraction efficiency (recovery $\sim 100 \%) .{ }^{\mathbf{5 2 , 9 0 , 9 1}}$ It is worth noting that the natural abundance of the two $\mathrm{V}$ isotopes differs enormously $\left({ }^{51} \mathrm{~V} /{ }^{50} \mathrm{~V}=415\right)$. Thus, in the MC-ICP-MS measurement, it is difficult to obtain appropriate signal intensities for both ${ }^{50} \mathrm{~V}$ and ${ }^{51} \mathrm{~V}$. To overcome this problem, Nielsen et al. equipped the Faraway cups with $10^{9} \Omega$ and $10^{11} \Omega$ resistors to detect the signals of ${ }^{51} \mathrm{~V}$ and ${ }^{50} \mathrm{~V}$, respectively, and achieved a high precision of $\mathrm{V}$ isotopic compositions $\left(2 \mathrm{SD}=0.15 \%\right.$ ).$^{52}$ Afterwards, the same group changed the resistor pairs of $10^{9}$ and $10^{11} \Omega$ to $10^{10}$ and $10^{12} \Omega$ and achieved a higher sensitivity in the $\mathrm{V}$ isotope measurement. ${ }^{53}$

The MC-ICP-MS methods for V isotopic analysis were applied in studies of different geological processes, including the $\mathrm{V}$ isotope fractionation in the processes of mantle melting, ${ }^{93}$ pyromagma, ${ }^{94}$ and the adsorption on the minerals. ${ }^{95}$ It was found that $\mathrm{V}$ is largely enriched in crude oil and $\mathrm{V}$ stable isotopes can provide evidence for the formation and storage of crude oil. ${ }^{96}$

In addition to the applications in the geochemical field, $\mathrm{V}$ isotopes have also been applied in biological process studies. $\mathrm{V}$ is an essential element in living organisms. $\mathrm{V}$ ions are counter ions for proteins and co-factors for some enzymes. $\mathrm{V}$ may switch easily among multiple valence states $(+2,+3,+4$, and +5$)$ in some bio-chemical reactions, ${ }^{97}$ and a large degree of $\mathrm{V}$ stable isotope fractionation may occur during bio-related processes. Malinovsky et al. developed a V isotopic analytical method in biological samples with $\mathrm{Fe}$ as an internal standard to correct the instrumental mass bias. The precision was $0.28 \%$ o (2SD), which was compromised by the complex biological matrix..$^{98}$ They also showed the potential applications of $\mathrm{V}$ isotopes to distinguish different origins of Amanita muscaria. ${ }^{98}$ For the biological application of $\mathrm{V}$ isotopes, the precision of $\mathrm{V}$ isotopic analysis in biological systems by MC-ICP-MS still needs to be further improved. In the measurement of $\mathrm{V}$ isotope ratios, $\mathrm{V}$ solutions supplied by Alfa Aesar (Massachusetts, USA) and NIST 3165 were often used as the reference bracketing standard solutions, but they need to be further certified.

\subsection{Barium}

$\mathrm{Ba}$ is an alkaline earth metal element with seven naturally occurring stable isotopes, ${ }^{130} \mathrm{Ba}(0.1058 \%),{ }^{132} \mathrm{Ba}(0.1012 \%)$, ${ }^{134} \mathrm{Ba}(2.417 \%),{ }^{135} \mathrm{Ba}(6.592 \%),{ }^{136} \mathrm{Ba}(7.853 \%),{ }^{137} \mathrm{Ba}(11.232 \%)$, and ${ }^{138} \mathrm{Ba}(71.699 \%)$. The first report on the analysis of the $\mathrm{Ba}$ isotopic composition was published in 1939. Over a long period of time, the precision for the determination of $\mathrm{Ba}$ isotope ratios could just reach $1 \%$ (2SD). Until 2010, von Allmen et al. reported a high precision method for the determination of the $\mathrm{Ba}$ stable isotopic composition by using the ${ }^{130} \mathrm{Ba}-{ }^{135} \mathrm{Ba}$ double 
spike technique and MC-ICP-MS with the 2SD of $0.15 \%{ }^{99}{ }^{99}$ More recently, Miyazaki et al. excluded the isobaric interference from ${ }^{130} \mathrm{Xe}$ and ${ }^{134} \mathrm{Xe}$ in the $\mathrm{Ba}$ isotope ratio analysis and improved the precision to $0.03 \%$ o (2SD). ${ }^{\mathbf{1 0 0}}$ For Ba isotopes, there are still no generally accepted SRMs. Nan et al. and Zuilen et al. measured the $\mathrm{Ba}$ isotopic compositions of different reference materials, including BCR-2, BHVO-2, JB-2, W-2, AGV-1, JA-2, RGM-1, GSP-2, G-2, BHVO-1, QLO-1, BIR-1, JG-1a, JB-1a, JR-1, JA-1, IAEA-SO-5, IAEA-SO-6, and IAEA-CO-9, ${ }^{\mathbf{1 0 1 - 1 0 3}}$ and an interlaboratory comparison was conducted to investigate the accuracy of the results. The $\mathrm{Ba}$ isotopic composition of the reference materials was relative to the standard reference material NIST SRM 3104a.

To date, the precision of the Ba stable isotopic analysis was overall satisfactory (2SD: $0.03 \%$ ), and Ba isotope fractionation was observed in various geochemical processes, including the diffusion and adsorption processes at low temperature, ${ }^{\mathbf{1 0 4}}$ mineral dissolution, and precipitation. ${ }^{\mathbf{1 0 5}}$ The Ba isotope fractionation and its mechanisms have been applied as useful tracers in studying geological and marine systems, ${ }^{\mathbf{1 0 3 , 1 0 6}}$ such as nutrient bio-lifting in pedogenic process, ${ }^{\mathbf{1 0 7}}$ the behaviors of sediment-derived fluids ${ }^{99}$ and the oceanic Ba cycle. ${ }^{108,109}$ Recent studies have found the significant variations in the Ba isotopic compositions of the seawater at different depths and different locations. ${ }^{109,110}$ These results reveal the potential of the use of $\mathrm{Ba}$ stable isotopes as novel tracers in studying the Ba inputs and utilization in the global ocean. ${ }^{\mathbf{1 1 1}}$ Nevertheless, until now, the behaviors of $\mathrm{Ba}$ in the ocean are still poorly understood due to the limited $\mathrm{Ba}$ isotope data in seawater. It is also worth noting that the Ba isotopic composition of NIST SRM 3104a has not been certified. Hence, the certified reference materials of $\mathrm{Ba}$ isotopes are in urgent demand for the analysis and applications of $\mathrm{Ba}$ isotopes.

\subsection{Potassium}

$\mathrm{K}$ is a common alkali metal element and plays important roles in a wide range of disciplines, such as climate, nutrient cycling, and human cardiovascular systems. $\mathrm{K}$ is composed of three naturally occurring isotopes: ${ }^{39} \mathrm{~K}(93.26 \%),{ }^{40} \mathrm{~K}(0.01 \%)$, and ${ }^{41} \mathrm{~K}$ $(6.73 \%) .{ }^{39} \mathrm{~K}$ and ${ }^{41} \mathrm{~K}$ are stable isotopes and ${ }^{40} \mathrm{~K}$ is a radioactive isotope. $^{112}$ Until now, researches on the analysis of the $\mathrm{K}$ isotopic composition with MC-ICP-MS are rare, because it is extremely difficult to eliminate the interference caused by ${ }^{40} \mathrm{Ar}$ and the mass interference of ${ }^{40} \mathrm{ArH}$ on ${ }^{41} \mathrm{~K}$ and ${ }^{38} \mathrm{ArH}$ on ${ }^{39} \mathrm{~K}$ in MS. ${ }^{113}$ Despite that, efforts were made to achieve the highly accurate and precise determination of the ${ }^{41} \mathrm{~K} /{ }^{39} \mathrm{~K}$ ratio by MC-ICP-MS in a pseudo-high resolution mode. Lowering the power of the plasma to reduce the ArH production and mixing with a collision gas to dissociate the molecular ions were found to effectively improve the accuracy and precision of $\mathrm{K}$ isotope analysis. ${ }^{114-118}$ In addition, the lack of certified SRMs limits the studies on $\mathrm{K}$ stable isotopes. Wang et al. used the "synthetic standards" prepared from highly enriched isotope standards $\left({ }^{39} \mathrm{~K}\right.$ and $\left.{ }^{41} \mathrm{~K}\right)$ to determine the $\mathrm{K}$ isotopic compositions of three basaltic rocks (BCR-2, BHVO-1, and CHEPR). ${ }^{113}$ Then, they also defined a Bulk Silicate Earth (BSE) value for $\mathrm{K}$ isotopes relative to the three basaltic rocks (BCR-2, BHVO-1, and CHEPR). ${ }^{119}$ Besides, NIST SRM 3141a was also employed as a standard material by Li et al. to analyze the $\mathrm{K}$ isotopic composition of geological and biological samples. ${ }^{112}$

So far, the precision of the $\mathrm{K}$ stable isotope measurement could reach $0.14 \%$ o (2SD), making it possible to explore the $\mathrm{K}$ isotope fractionation occurring in the natural environment or biogeochemical processes using MC-ICP-MS. ${ }^{112}$ Highly accurate and precise $\mathrm{K}$ isotope ratios were used as appropriate probes to reveal the physical and chemical conditions in the processes of Moon-forming. Wang et al. obtained the high-precision $\mathrm{K}$ isotopic composition of the Earth, Moon and chondritic meteorites and found the significant $\mathrm{K}$ isotope fractionation in the Moon compared to the Earth. ${ }^{119}$ This might be caused by the depletion of the volatile elements close to the formation of the Moon. Parendo et al. used the $\mathrm{K}$ isotope ratios as an effective tracer to reveal the recycle of the oceanic crust into the mantle. ${ }^{\mathbf{1 2 0}}$ Considering the special role of $\mathrm{K}$ in the hydrothermal processes, they investigated the $\mathrm{K}$ isotopic composition of the samples collected from the Bay of Islands ophiolite. The distinct variations in the $\mathrm{K}$ isotopic composition of the oceanic crust revealed the effects caused by seafloor hydrothermal alteration. $\mathrm{Li}$ et al. appealed to pay close concern on the $\mathrm{K}$ isotope fractionation in some biological activities of plants. ${ }^{121}$ They found that the $\mathrm{K}$ isotope variations in biological samples were larger than those in geological samples and hypothesized that $\mathrm{K}$ isotope fraction may occur in the $\mathrm{K}$ uptake processes of plants.

\subsection{Platinum}

Pt is a transition metal element with six naturally occurring stable isotopes, ${ }^{190} \mathrm{Pt}(0.01 \%),{ }^{192} \mathrm{Pt}(0.78 \%),{ }^{194} \mathrm{Pt}(32.86 \%)$, ${ }^{195} \mathrm{Pt}(33.78 \%),{ }^{196} \mathrm{Pt}(25.21 \%)$, and ${ }^{196} \mathrm{Pt}(7.36 \%) .{ }^{122}$ The Pt isotopes were used as potential tracers to explore the redox processes in surficial and marine environments over a long period of time. ${ }^{123}$ In addition, Pt agents are widely used in medical and industrial fields. ${ }^{\mathbf{1 2 4 - 1 2 7}} \mathrm{Pt}$ is also a common catalyst widely applied in the automotive industry ${ }^{\mathbf{1 2 8 , 1 2 9}}$ and can be used as a marker to monitor the vehicle emission. ${ }^{\mathbf{1 3 0 , 1 3 1}}$ As a result, $\mathrm{Pt}$ isotopes are expected to be novel tracers for different purposes, such as studying the global Pt biogeochemical cycle and tracing the climate changes of the marine and atmospheric chemistry. ${ }^{123}$ However, the current research studies on Pt isotopes are still very few because of the lack of Pt isotopic analytical methods. The first report on the Pt isotope ratio measurement was conducted with TIMS by White et al. in $1956 .{ }^{132}$ Then, other techniques were also developed to measure Pt isotope ratios, including gas source mass spectrometry, negative TIMS, quadrupole inductively coupled plasma mass spectrometry (Q-ICPMS), and inductively coupled plasma time of flight mass spectrometry (ICP-TOF-MS). ${ }^{\mathbf{1 3 3 - 1 4 0}}$ However, accuracy and precision were not satisfactory. In 2013, a highly accurate and precise method for the determination of Pt isotope ratios with MC-ICPMS was reported by Creech et al. using the ${ }^{192} \mathrm{Pt}-{ }^{198} \mathrm{Pt}$ and ${ }^{196} \mathrm{Pt}-{ }^{198} \mathrm{Pt}$ double spike technique. ${ }^{\mathbf{1 2 3}}$ They developed a purification procedure with ion-exchange columns and reported the Pt isotopic compositions of 11 terrestrial SRMs relative to the 
isotope SRM IRMM-010. The precision of the measurement for rock samples was $0.088 \%$ (2SD), which ensured the use of $\mathrm{Pt}$ isotopes as a practical tool in a wide range of research fields. ${ }^{\mathbf{1 4 1}}$ Similar to $\mathrm{V}$ isotopes, the low abundance of ${ }^{190} \mathrm{Pt}(0.014 \%)$ caused large uncertainties to the Pt isotopic analysis. Peters et al. equipped the Faraday amplifiers of MC-ICP-MS with $10^{12} \Omega$ resistors and obtained high precision $\left(2 \mathrm{SD}=0.1 \%\right.$ ) in ${ }^{190} \mathrm{Pt}$ isotopic analysis. ${ }^{54}$

\subsection{Palladium}

Pd locates at the same group as Pt in the periodic table of elements. It has six naturally occurring stable isotopes: ${ }^{102} \mathrm{Pd}$ (1.02\%), ${ }^{104} \mathrm{Pd}(11.14 \%),{ }^{105} \mathrm{Pd}(22.33 \%),{ }^{106} \mathrm{Pd}(27.33 \%),{ }^{108} \mathrm{Pd}$ (26.46\%), and ${ }^{110} \mathrm{Pd}(11.72 \%)$. Similar to Pt, Pd is widely applied in automobile exhaust catalysts and contributes to the reduction of the emission of carbon monoxide, hydrocarbons, and nitrogen oxides. ${ }^{142,143}$ It was found that Pd is widely present in ultra-fine atmospheric particles, road dust, and roadside vegetation. ${ }^{\mathbf{1 4 4 - 1 4 7}}$ The major obstacles for the analysis of Pd stable isotope ratios are the isobaric mass interference caused by $\mathrm{Ru}$ $\left({ }^{102} \mathrm{Ru}\right.$ and $\left.{ }^{104} \mathrm{Ru}\right)$ and $\mathrm{Cd}\left({ }^{106} \mathrm{Cd},{ }^{108} \mathrm{Cd}\right.$, and $\left.{ }^{110} \mathrm{Cd}\right)$ and the molecular ion interference caused by the hydrides of $\mathrm{Rh}\left(\mathrm{RhH}^{+}\right)$ and $\mathrm{Ag}\left(\mathrm{AgH}^{+}\right)$, Ar compounds of $\mathrm{Ni}\left(\mathrm{NiAr}^{+}\right)$and $\mathrm{Zn}\left(\mathrm{ZnAr}^{+}\right)$, and oxides of $\mathrm{Zr}$ (ZrO) and $\mathrm{Mo}(\mathrm{MoO}) .{ }^{148}$ Similar purification procedures with the Pt group elements could be used to purify the geological samples for the Pd concentration measurement. ${ }^{\mathbf{1 4 9}}$ Ek et al. developed an ion exchange separation method to achieve a highly efficient removal of $\mathrm{Ru}(\mathrm{Ru} / \mathrm{Pd}<0.0005), \mathrm{Cd}$ (Cd/Pd < 0.025), Ni ( Ni/Pd < 0.04), Zr ( Zr/Pd < 0.0002), and Zn $(\mathrm{Zn} / \mathrm{Pd}<0.06)$ from the samples for Pd isotopic analysis. ${ }^{150} \mathrm{By}$ using this method, they measured the Pd isotopic compositions in iron meteorite samples with the precision between $0.01 \%$ o and $0.12 \%$. Creech et al. developed a ${ }^{106} \mathrm{Pd}-{ }^{110} \mathrm{Pd}$ double spike calibration procedure to achieve highly precise determination (2SD $=0.032 \%$ for ${ }^{106} \mathrm{Pd}$ ) of Pd isotope ratios and measured the $\mathrm{Pd}$ isotopic compositions of terrestrial and extraterrestrial samples. ${ }^{151}$

It is noteworthy that the MIF of Pd isotopes was observed in the processes of chemical exchange reactions probably caused by the nuclear field shift effect. ${ }^{152}$ The MIF of Pd may strengthen the capability of Pd stable isotopes in source tracing and processing studies of Pd in the environment. Like other emerging isotopes, Pd isotopes also lack generally accepted isotopic SRMs. In a recent study on Pd isotopes, the isotopic composition of NIST 3138 Pd standard solution analyzed over long term was chosen as the temporary reference material. ${ }^{150}$

\subsection{Silver}

$\mathrm{Ag}$ is an adjacent element to Pd with two naturally occurring isotopes: ${ }^{107} \mathrm{Ag}(51.8 \%)$ and ${ }^{109} \mathrm{Ag}(48.2 \%) .{ }^{153}$ In recent years, $\mathrm{Ag}$ has shown increasing environmental implications due to the rapidly increasing production, usage, and disposal levels of engineered $\mathrm{Ag}$ nanoparticles (AgNPs). ${ }^{154}$ Particularly, recent studies have revealed that AgNPs are potentially harmful for organisms and human health and that AgNPs can influence the ecosystems. ${ }^{155} \mathrm{Ag}$ has only two stable isotopes and this limits the use of the double spike technique to correct the mass bias in MC-ICP-MS. Yang et al. developed a high accuracy and precision method for the determination of $\mathrm{Ag}$ stable isotope ratios in environmental samples based on the SSB technique combined with the use of Pd as an internal standard. ${ }^{84}$ That is, the ${ }^{108} \mathrm{Pd} /{ }^{106} \mathrm{Pd}$ ratio was used to correct the mass bias of the ${ }^{109} \mathrm{Ag} /{ }^{107} \mathrm{Ag}$ ratio. As there are no isotopic SRMs for Pd, the mass bias of the ${ }^{108} \mathrm{Pd} /{ }^{106} \mathrm{Pd}$ ratio in two adjacent $\mathrm{Ag}$ isotope standard solutions (SRM 978a) was first corrected by the certified value of ${ }^{107} \mathrm{Ag} /{ }^{109} \mathrm{Ag}$ in SRM 978a, and then their average value was used for the correction of the ${ }^{109} \mathrm{Ag} /{ }^{107} \mathrm{Ag}$ ratio in the sample. They also developed a two-stage tandem column method to purify the $\mathrm{Ag}$ from environmental samples and obtained a high precision of $0.01 \%$ (2SD) in $\mathrm{Ag}$ isotope ratio analysis. ${ }^{18,51}$

The lack of sufficient isotopic SRMs also adversely affected the $\mathrm{Ag}$ isotope ratio analysis. For isotope ratio analysis, it is ideal to validate the methods with two isotope SRMs. However, till now, there are no secondary isotopic SRMs for Ag besides SRM 978a. In fact, the lack of sufficient isotopic SRMs is a common problem in high precision isotope ratio analysis. To guarantee the accuracy of the $\mathrm{Ag}$ isotope ratio measurement in the absence of enough isotopic SRMs, Liu et al. examined the isotopic mass balance in the natural transformation process of AgNPs. ${ }^{156}$

\subsection{Cerium}

Ce is an important rare earth element with four naturally occurring stable isotopes: ${ }^{136} \mathrm{Ce}(0.186 \%),{ }^{138} \mathrm{Ce}(0.251 \%),{ }^{140} \mathrm{Ce}$ $(88.449 \%)$, and ${ }^{142} \mathrm{Ce}(11.114 \%)$. Similar to $\mathrm{Ag}$, Ce has attracted much research attention because of the large production and usage amount of engineered cerium oxide nanoparticles $\left(\mathrm{CeO}_{2}\right.$ NPs), which arises significant environmental concerns. ${ }^{157}$ The sources and fate of $\mathrm{CeO}_{2}$ NPs in the environment are still poorly understood and this calls for new tracing tools. ${ }^{\mathbf{1 5 8}}$ For high precision determination of Ce isotope ratios in environmental and geological samples, a major obstacle is the lack of certified isotope SRMs. The JMC304 Ce reagent (Johnson Matthey Catalyst) and $\mathrm{CeCl}_{3}$ reagent (Wako, Japan) were employed as reference materials in the current studies. ${ }^{159,160}$ For reference, Takeshi et al. determined the Ce isotopic composition of five geological reference materials, including JB-1a, JA-2, JMn-1, JCh-1, and JDo-1. ${ }^{\mathbf{1 6 1}}$ Another obstacle for Ce isotope analysis is the matrix interference. Particularly, similar chemical properties of Ce with other rare earth elements lead to extreme difficulties in the sample purification procedures. Tazoe et al. developed a highly efficient purification protocol based on the oxidative adsorption of different Ce oxidation states onto the chelating resin. ${ }^{159}$ The precision of the ${ }^{142} \mathrm{Ce} /{ }^{140} \mathrm{Ce}$ ratio measurement with MC-ICP-MS could reach $0.04 \%$ (2SD) with $\mathrm{Ba}$ as an internal standard for $\mathrm{CeO}_{2} \mathrm{NPs}$, and the precision for the determination of the ${ }^{138} \mathrm{Ce} /{ }^{142} \mathrm{Ce}$ ratio normalized with ${ }^{18} \mathrm{O} /{ }^{16} \mathrm{O}$ could reach $0.18 \%$ o (2SD) for rock samples. Note that the ${ }^{135} \mathrm{Ba} /{ }^{137} \mathrm{Ba}$ did not cause isobaric interference to the measurement of ${ }^{142} \mathrm{Ce} /{ }^{140} \mathrm{Ce}$ and can be used as an internal standard to correct the mass bias. While for the measurement of ${ }^{138} \mathrm{Ce} /{ }^{142} \mathrm{Ce}, \mathrm{Ba}, \mathrm{Ba}$ oxides, and Ce oxides may cause isobaric 
interference: e.g., ${ }^{140} \mathrm{Ce}^{18} \mathrm{O}$ is interfered by ${ }^{142} \mathrm{Ce}^{16} \mathrm{O} .{ }^{162,163} \mathrm{Ohno}$ et al. developed another highly precise Ce isotope $\left({ }^{142} \mathrm{Ce} /{ }^{140} \mathrm{Ce}\right)$ analytical method by using $\mathrm{Sm}\left({ }^{149} \mathrm{Sm} /{ }^{147} \mathrm{Sm}\right)$ as an internal standard to correct the mass discrimination. They achieved a precision of $0.08 \%$ o (2SD) to investigate the Ce isotopic composition of carbonate samples, igneous rocks, and sedimentary rocks. ${ }^{161}$

Driven by the highly accurate and precise analytical method for the determination of Ce isotope ratios, Ce isotope fractionation has been used to investigate the geochemical and physicochemical processes. For example, Nakada et al. used Ce isotopes as a proxy to estimate the redox state of the paleooceanic environment and the atmospheric evolution. ${ }^{160,164}$ Tazoe et al. have also applied the Ce isotopes as useful tracers to study the cosmochemical processes. ${ }^{159}$

\subsection{Erbium}

Er is a rare earth element normally present in the form of ErO. It has six naturally occurring stable isotopes: ${ }^{162} \mathrm{Er}(0.139 \%),{ }^{164} \mathrm{Er}$ (1.601\%), ${ }^{166} \operatorname{Er}(33.503 \%),{ }^{167} \operatorname{Er}(22.869 \%),{ }^{168} \operatorname{Er}(26.978 \%)$, and ${ }^{170} \operatorname{Er}(19.910 \%) .{ }^{165}$ The ionization potential of $\mathrm{Er}$ is $6.20 \mathrm{eV}$ that is lower than the appropriate ionization potential for the measurement with TIMS ( $7 \mathrm{eV})$. Thus, the Er isotopic compositions can be determined by TIMS. ${ }^{165,166}$ Compared with TIMS, MC-ICP-MS has advantages of higher sample throughput and higher precision. Albalat et al. developed a method for Er isotope ratio analysis with MC-ICP-MS, and the precision could reach $0.07 \%$ (2SD). They also applied Er isotopic analysis in the deduction of the effect of the neutron capture. ${ }^{167}$ For instance, the ${ }^{167} \mathrm{Er}$ can capture the neutron to produce ${ }^{168} \mathrm{Er}$, which was found to cause the MIF of Er isotopes. Therefore, Er isotopes can be used to explore the occurrence of the neutron capture in some unknown astronomical process. Similar to other emerging isotopes, Er isotopes also suffer from the lack of certified isotope SRMs. For reference, Emmanuelle et al. reported the Er isotopic composition of Hawaiian basalt BHVO-2 (USGS reference material). ${ }^{167}$

\subsection{Silicon}

$\mathrm{Si}$ is the second most abundant element in the Earth's crust. $\mathrm{Si}$ has three naturally occurring stable isotopes: ${ }^{28} \mathrm{Si}(92.22 \%),{ }^{29} \mathrm{Si}$ $(4.69 \%)$, and ${ }^{30} \mathrm{Si}(3.09 \%)$. Although Si stable isotopes have a long research history over 50 years, the analysis of Si isotope ratios was always thought as a challenging task due to the high background signals and serious mass interference from sample matrix and other elements. ${ }^{2}$ Conventional methods for the measurement of $\mathrm{Si}$ isotope ratios need a complicated and timeconsuming sample pretreatment and require the use of hazardous chemicals $\left(\mathrm{F}_{2}\right.$ or $\left.\mathrm{BrF}_{5}\right){ }^{168} \mathrm{Georg}$ et al. ${ }^{23}$ and Zambardi et al. ${ }^{169}$ developed highly accurate and precise methods for $\mathrm{Si}$ isotope ratio measurement free of the use of $\mathrm{F}_{2} \mathrm{Or} \mathrm{BrF}_{5}$ reagents. The precision of the measurement reached $0.10 \%$ and $0.07 \%$ (2SD). The high precision Si isotopic analytical methods in solid siliceous materials are of great help for investigating some important geological processes, such as silicate weathering, ${ }^{170,171}$ global climate, and paleoceanography. ${ }^{172}$ However, the $\mathrm{Si}$ isotope ratio measurements in natural water are more challenging than those in solid materials due to the low concentration of $\mathrm{Si}$ in natural waters and the lack of sufficient certified Si isotopic reference materials.

To solve these problems, Engström et al. used the anionexchange chromatography to pre-concentrate the dissolved silicon (DSi) from the natural surface water and achieved the accurate and precise $\left(2 \mathrm{SD}\right.$ for ${ }^{29} \mathrm{Si}=0.18 \%$ ) $\mathrm{Si}$ isotopic analysis by MC-ICP-MS. ${ }^{173}$ They also investigated the temporal variations in the DSi isotopic composition of the boreal Kalix River system and revealed the potential impacts of the origins and processes of $\mathrm{Si}$ on the riverine $\mathrm{Si}$ isotope budget. ${ }^{174}$ Moreover, a magnesium induced co-precipitation (MAGIC) method was developed to pre-concentrate $\mathrm{Si}$ in water samples. ${ }^{23,175-177}$ Briefly, sodium hydroxide $(\mathrm{NaOH})$ and $\mathrm{Mg}$ ion were added to the target water samples with a low content of $\mathrm{Si}$ to form brucite $\left(\mathrm{Mg}(\mathrm{OH})_{2}\right)$. Then, the brucite could remove the $\mathrm{Si}(\mathrm{OH})_{4}$ from the sample solutions and enrich the Si for isotope analysis. Zhang et al. further optimized the MAGIC method by changing the $\mathrm{NaOH}$ to ammonium hydroxide $\left(\mathrm{NH}_{3} \cdot \mathrm{H}_{2} \mathrm{O}\right)$, which significantly improved the enrichment factor and separation efficiency of $\mathrm{Si}$ in water samples by a single pre-concentration and purification procedure. ${ }^{176}$ The recovery of Si could approximate to $100 \%$. Recently, Yang et al. optimized the sample pretreatment procedures by on-line coupling ion exclusion chromatography to MC-ICP-MS. ${ }^{62}$ The method was also successfully applied in analysis of real environmental water samples.

Although several isotopic SRMs for $\mathrm{Si}$ in solid samples have been well certified, such as NIST 8546, IRMM-017, IRMM-018, GBW04421, and GBW04422, ${ }^{23,169,177}$ the SRMs for Si isotopes in liquid samples are insufficient. Grasse et al. conducted an intercalibration study of the Si isotopic composition of dissolved silicic acid in seawater. ${ }^{178}$ Two sets of seawater samples collected from the North Pacific subtropical gyre (Station ALOHA) were analyzed by 11 laboratories from 7 countries. Although a good agreement among laboratories was observed, small but significant inter-laboratory differences were obtained due likely to different sample pretreatment methods and different analytical instruments used. This study demonstrated the importance of the use of multiple SRMs in Si isotope ratio analysis.

\section{Novel applications of non- traditional stable isotopes}

From the progress summarized above, we can learn that the rapid development of the MC-ICP-MS technique greatly enhanced the accuracy and precision of non-traditional stable isotopic analysis, which expanded the application range of nontraditional stable isotopes to various new fields beyond geosciences, archaeology, anthropology and environmental sciences. Here, we introduce two novel application fields of nontraditional stable isotopes.

\subsection{Applications of non-traditional stable isotopes in nanotechnology}

Non-traditional stable isotopes are new promising tools for nanotechnology research. The processes of metal nanoparticles 
in the environment, such as formation, dissolution, precipitation, complexation, sorption/desorption, and accumulation, may cause significant isotope fractionation, and we can get new insights into the behaviors and fate of the nanoparticles from the analysis of the natural isotopic compositions.

A recent study by Liu et al. reported that the natural formation and dissolution of AgNPs in natural water could cause significant $\mathrm{Ag}$ isotope fractionation. ${ }^{156}$ AgNPs could form through the reduction of $\mathrm{Ag}^{+}$ions in the presence of dissolved organic matter, and the dissolution of AgNPs could release $\mathrm{Ag}^{+}$ ions. They showed that these processes are accompanied by $\mathrm{Ag}$ isotope fractionation with an isotopic enrichment factor up to $0.86 \%$. The $\mathrm{Ag}$ isotope fractionation provides a novel means to infer the transformation pathways of AgNPs in the environment. Furthermore, they found that engineered AgNPs showed different isotope fractionation effects from the naturally formed AgNPs, thus revealing the possibility of using Ag isotope fractionation to distinguish the sources of AgNPs in the environment. This study showed that the natural stable isotopes are reliable tools to detect, characterize, and trace the behaviors and fate of the nanoparticles in the environment. Besides Ag, other stable isotope systems, such as $\mathrm{Ce}, \mathrm{Cu}$, and $\mathrm{Zn}$, have also been used to study the fate and sources of engineered nanoparticles $\left(\mathrm{CeO}_{2}, \mathrm{CuO}\right.$, and $\mathrm{ZnO}$ NPs $) .{ }^{\mathbf{1 6 2 , 1 7 9 - 1 8 1}}$ Although the use of stable isotopes in nanotechnology research is just at its very beginning stage, the importance of this research area is substantial taking into account the evident environmental concerns of engineered nanomaterials due to the increasing usage and disposal levels of the engineered nanomaterials.

\subsection{Applications of non-traditional stable isotopes in environmental health studies}

Natural stable isotopes can be used as promising markers to elucidate the influences of environmental pollution on the human health. A series of biogenic processes, including the biomethylation, bioalkylation, biomineralization, and bioaccumulation, may cause isotope fractionation, and we can deduce the underlying pathways and mechanisms of the health effects via determining the isotope variations of related elements. ${ }^{\mathbf{1 8 2}}$

For example, the Fe stable isotopic composition in blood was used as a potential biomarker for diagnosis of hereditary hemochromatosis. ${ }^{183}$ The blood of hereditary hemochromatosis patients was found to be Fe-isotopically heavier than healthy individuals due to isotope-sensitive intestinal Fe intake. The Ca isotopic composition in the urine of the bone loss patients was detected and compared with the healthy person. ${ }^{\mathbf{1 8 4}}$ It was found that monitoring the changes in $\mathrm{Ca}$ isotope ratios could help in the detection of the onset of bone loss much more quickly than using densitometry. Thus, the Ca isotope analysis may provide a valuable approach for early diagnosis of metabolic bone diseases. In addition, the lighter $\mathrm{Cu}$ isotope $\left({ }^{63} \mathrm{Cu}\right)$ was found to be enriched in the blood of hepatocellular carcinoma (HCC) patients compared with the healthy individuals due to the massive reallocation and immobilization of $\mathrm{Cu}$ within cysteinerich proteins. ${ }^{\mathbf{1 8 5}}$ Recently, Li et al. found the large variation on $\mathrm{K}$ isotopic compositions during the cell uptake processes of $\mathrm{K}^{\mathbf{1 2 1}}$ The $\mathrm{K}$ isotopes may provide a meaningful tool for the environmental health studies considering the importance of $\mathrm{K}$ in the living organisms. Besides, the significant isotope fractionation of the $\mathrm{Si}$ and $\mathrm{V}$ were also reported in some bio-related processes. ${ }^{\mathbf{9 8 , 1 8 6 , 1 8 7}}$ These studies have demonstrated the feasibility of using natural stable isotopes as potentially powerful tools in environmental health studies. To further push on the application of non-traditional stable isotopes in this field, more environmental epidemiological investigations are demanded to link environmental risk factors (e.g., heavy metals) with diseases.

\section{Conclusions and perspectives}

MC-ICP-MS is one of the most important techniques for isotope analysis. The rapid development of the MC-ICP-MS technique strengthens the power of stable isotopes as important tools in various fields. Meanwhile, the increasing use of stable isotopes calls for more innovations in MC-ICP-MS methodology and instrumentation. In recent years, more and more MC-ICP-MS methods were developed for highly accurate and precise measurement of stable isotope ratios beyond traditional $\mathrm{C}, \mathrm{H}$, $\mathrm{O}, \mathrm{N}$, and $\mathrm{S}$ isotopes. The improvement in analytical sensitivity and sample purification techniques greatly enhanced the analytical capability of MC-ICP-MS for real complex samples. These advances extended the application range of nontraditional stable isotopes to some emerging research fields, such as nanotechnology and environmental health science, in which non-traditional stable isotopes are regarded as revolutionary new tools. Undoubtedly, non-traditional stable isotopes will play prominent roles in a wide variety of fields, and MC-ICPMS will continue to serve as the key technique in the stable isotope analysis.

At the same time, we must be aware that the application of non-traditional stable isotopes is still to be explored with many challenges remaining in their analytical methods. To make nontraditional stable isotopes, more reliable and generally accepted tools in different fields, future efforts should be made in the following aspects:

(1) Development of more certified isotopic SRMs for nontraditional stable isotopes: Although in-house standard materials can be used in special cases, generally accepted or commercially available certified SRMs are certainly more popular and favorable for other researchers to understand and repeat the experiments. As mentioned above, unfortunately, many elements are short of sufficient isotopic SRMs to allow an easy inter-laboratory validation of the method. Some elements have only one isotopic SRM (e.g., Ag), or, frequently, have no available certified isotopic SRMs (e.g., V, Ba, and Pd). This situation seriously limits the research on and the application of non-traditional stable isotopes. Therefore, as a primary goal in non-traditional isotopic chemistry, development of more certified isotopic SRMs for non-traditional stable isotopes makes great sense.

(2) Further improvement of the performance of MC-ICP-MS: Although MC-ICP-MS has shown its unique superiority over 
other techniques, its performance still needs to be improved, particularly regarding the analysis in real complex environmental or biological samples, in which the target elements are normally present at an extremely low concentration (e.g., Ag and $\mathrm{Hg}$ ). Furthermore, the accuracy and precision of MC-ICP-MS for many stable isotopes still need to be optimized to detect subtle stable isotope fractionation in the environment.

(3) Simplification of the analytical procedures with MC-ICPMS: A complete protocol for MC-ICP-MS analysis includes multiple steps, such as sample purification and introduction, mass bias correction, instrumental parameter optimization, and data processing. These steps require much time and operational experience, preventing MC-ICP-MS from being an easily accessible technique. Therefore, future efforts should be devoted to make the methods quicker, economical, automatic, and easier to operate.

(4) Development of isotope analytical methods toward more non-traditional elements: A considerable part of elements that have natural stable isotopes still lack suitable methods to measure their isotope ratios. The isotopic analysis may help understand the biogeochemical cycles and natural process of these elements. For example, gadolinium (Gd) plays an important role in modern medicine and also has significant environmental implications. ${ }^{188,189}$ However, the analytical method for the determination of Gd isotope ratios is still unreported. With the further recognition of the importance of these elements, the analytical methods for their stable isotopes are highly desired. Only in that way will the MC-ICP-MS technique find its position in a wider range of research fields.

\section{Conflicts of interest}

There are no conflicts to declare.

\section{Acknowledgements}

This work was financially supported by the Chinese Academy of Sciences (No. XDB14010400, QYZDB-SSW-DQC018), the National Basic Research Program of China (2015CB931903, 2015CB932003), and the National Natural Science Foundation of China (No. 91543104, 21377141, 21422509). Qian Liu acknowledges the support from the Youth Innovation Promotion Association of CAS.

\section{References}

$1 \mathrm{~J}$. Hoefs, Stable Isotope Geochemistry, Springer, 2015.

$2 \mathrm{M}$. Baskaran, Handbook of Environmental Isotope Geochemistry, Springer, 2012.

3 H. Yuan, S. Gao, X. Liu, H. Li, D. Günther and F. Wu, Geostand. Geoanal. Res., 2004, 28, 353-370.

4 S. F. Boulyga, D. Desideri, M. A. Meli, C. Testa and J. S. Becker, Int. J. Mass Spectrom., 2003, 226, 329-339.

5 S. F. Boulyga, M. Zoriy, M. E. Ketterer and J. S. Becker, J. Environ. Monit., 2003, 5, 661-666.

6 I. Günther-Leopold, J. K. Waldis, B. Wernli and Z. Kopajtic, Int. J. Mass Spectrom., 2005, 242, 197-202.
7 J. S. Becker, Int. J. Mass Spectrom., 2005, 242, 183-195.

8 V. N. Epov, K. Benkhedda, R. J. Cornett and R. D. Evans, J. Anal. At. Spectrom., 2005, 20, 424-430.

9 J. W. Ejnik, T. I. Todorov, F. G. Mullick, K. Squibb, M. A. McDiarmid and J. A. Centeno, Anal. Bioanal. Chem., 2005, 382, 73-79.

10 T. Walczyk and F. von Blanckenburg, Int. J. Mass Spectrom., 2005, 242, 117-134.

11 V. N. Epov, D. Malinovskiy, F. Vanhaecke, D. Begue and O. F. X. Donard, J. Anal. At. Spectrom., 2011, 26, 1142-1156.

12 J. G. Wiederhold, Environ. Sci. Technol., 2015, 49, 26062624.

13 F. Albarède and B. Beard, Rev. Mineral. Geochem., 2004, 55, 113-152.

14 C. Aeppli, H. Holmstrand, P. Andersson and Ö. Gustafsson, Anal. Chem., 2010, 82, 420-426.

15 F. Gelman and L. Halicz, Int. J. Mass Spectrom., 2010, 289, 167-169.

16 S. K. Sahoo and A. Masuda, Anal. Chim. Acta, 1998, 370, 215220.

17 A. J. Walder, I. Platzner and P. A. Freedman, J. Anal. At. Spectrom., 1993, 8, 19-23.

18 L. Yang, Mass Spectrom. Rev., 2009, 28, 990-1011.

19 C. B. Douthitt, Anal. Bioanal. Chem., 2008, 390, 437-440.

20 E.-K. Potter, C. H. Stirling, M. B. Andersen and A. N. Halliday, Int. J. Mass Spectrom., 2005, 247, 10-17.

21 T. I. Platzner, I. Segal and L. Halicz, Anal. Bioanal. Chem., 2008, 390, 441-450.

22 D. Buhl, A. Immenhauser, G. Smeulders, L. Kabiri and D. K. Richter, Chem. Geol., 2007, 244, 715-729.

23 R. Georg, B. Reynolds, M. Frank and A. Halliday, Chem. Geol., 2006, 235, 95-104.

24 M. E. Wieser, D. Buhl, C. Bouman and J. Schwieters, J. Anal. At. Spectrom., 2004, 19, 844-851.

25 J. S. Becker, J. Anal. At. Spectrom., 2005, 20, 1173-1184.

26 J. S. Becker, J. Anal. At. Spectrom., 2002, 17, 1172-1185.

27 D. C. Baxter, I. Rodushkin and E. Engström, J. Anal. At. Spectrom., 2012, 27, 1355-1381.

28 F. Vanhaecke and P. Degryse, Isotopic Analysis: Fundamentals and Applications Using ICP-MS, John Wiley \& Sons, 2012.

29 J. Irrgeher and T. Prohaska, Anal. Bioanal. Chem., 2016, 408, 369-385.

30 F.-Z. Teng, N. Dauphas and J. M. Watkins, Rev. Mineral. Geochem., 2017, 82, 1-26.

31 D. Malinovsky and F. Vanhaecke, Anal. Bioanal. Chem., 2011, 400, 1619-1624.

32 M. H. Thiemens, Annu. Rev. Earth Planet. Sci., 2006, 34, 217262.

33 M. H. Thiemens and J. E. Heidenreich, Science, 1983, 219, 1073-1075.

34 J. Farquhar, H. Bao and M. Thiemens, Science, 2000, 289, 756-758.

35 B. A. Bergquist and J. D. Blum, Science, 2007, 318, 417-420. 36 L. S. Sherman, J. D. Blum, K. P. Johnson, G. J. Keeler, J. A. Barres and T. A. Douglas, Nat. Geosci., 2010, 3, 173-177. 37 B. A. Bergquist and J. D. Blum, Elements, 2009, 5, 353-357. 
38 T. A. Jackson, D. M. Whittle, M. S. Evans and D. C. Muir, Appl. Geochem., 2008, 23, 547-571.

39 R. Yin, X. Feng and W. Shi, Appl. Geochem., 2010, 25, 14671477.

40 M. Wolfsberg, W. A. Van Hook, P. Paneth and L. P. N. Rebelo, Isotope Effects: In the Chemical, Geological, and Bio Sciences, Springer, 2009.

41 M. H. Thiemens, Science, 1999, 283, 341-345.

42 J. Farquhar, D. T. Johnston, B. A. Wing, K. S. Habicht, D. E. Canfield, S. Airieau and M. H. Thiemens, Geobiology, 2003, 1, 27-36.

43 E. Ponzevera, C. R. Quétel, M. Berglund, P. D. Taylor, P. Evans, R. D. Loss and G. Fortunato, J. Am. Chem. Soc., 2006, 17, 1413-1428.

44 H. Andrén, I. Rodushkin, A. Stenberg, D. Malinovsky and D. C. Baxter, J. Anal. At. Spectrom., 2004, 19, 1217-1224.

45 C. D. Coath, T. Elliott and R. C. Hin, Chem. Geol., 2017, 451, 78-89.

46 J. F. Rudge, B. C. Reynolds and B. Bourdon, Chem. Geol., 2009, 265, 420-431.

47 D. Vance and M. Thirlwall, Chem. Geol., 2002, 185, 227-240.

48 L. Yang, C. Peter, U. Panne and R. E. Sturgeon, J. Anal. At. Spectrom., 2008, 23, 1269-1274.

49 F. Albarede, P. Telouk, J. Blichert-Toft, M. Boyet, A. Agranier and B. Nelson, Geochim. Cosmochim. Acta, 2004, 68, 27252744.

50 T. F. Mason, D. J. Weiss, M. Horstwood, R. R. Parrish, S. S. Russell, E. Mullane and B. J. Coles, J. Anal. At. Spectrom., 2004, 19, 218-226.

51 Y. Luo, E. Dabek-Zlotorzynska, V. Celo, D. C. G. Muir and L. Yang, Anal. Chem., 2010, 82, 3922-3928.

52 S. G. Nielsen, J. Prytulak and A. N. Halliday, Geostand. Geoanal. Res., 2011, 35, 293-306.

53 S. G. Nielsen, J. D. Owens and T. J. Horner, J. Anal. At. Spectrom., 2016, 31, 531-536.

54 S. T. Peters, C. Münker, F. Wombacher and B.-M. Elfers, Chem. Geol., 2015, 413, 132-145.

55 J. G. Konter and L. P. Storm, Chem. Geol., 2014, 385, 26-34.

56 S. Weyer and J. Schwieters, Int. J. Mass Spectrom., 2003, 226, 355-368.

57 K.-F. Huang, C.-F. You, Y.-H. Liu, R.-M. Wang, P.-Y. Lin and C.-H. Chung, J. Anal. At. Spectrom., 2010, 25, 1019-1024.

58 M. Jiménez-Moreno, J. P. Barre, V. Perrot, S. Bérail, R. C. R. Martín-Doimeadios and D. Amouroux, Chemosphere, 2016, 147, 430-438.

59 S. Bérail, J. Cavalheiro, E. Tessier, J. Barre, Z. Pedrero, O. Donard and D. Amouroux, J. Anal. At. Spectrom., 2017, 32, 373-384.

60 M. Štrok, H. Hintelmann and B. Dimock, Anal. Chim. Acta, 2014, 851, 57-63.

$61 \mathrm{~J}$. Chen, H. Hintelmann and B. Dimock, J. Anal. At. Spectrom., 2010, 25, 1402-1409.

62 L. Yang, L. Zhou, Z. Hu and S. Gao, Anal. Chem., 2014, 86, 9301-9308.

63 M. Dzurko, D. Foucher and H. Hintelmann, Anal. Bioanal. Chem., 2009, 393, 345-355.
64 R. Yin, X. Feng, X. Li, B. Yu and B. Du, Trends Environ. Anal. Chem., 2014, 2, 1-10.

65 A. Rua-Ibarz, E. Bolea-Fernandez and F. Vanhaecke, Anal. Bioanal. Chem., 2016, 408, 417-429.

66 B. Bühn, M. M. Pimentel, M. Matteini and E. L. Dantas, An. Acad. Bras. Cienc., 2009, 81, 99-114.

67 H.-L. Yuan, S. Gao, M.-N. Dai, C.-L. Zong, D. Günther, G. H. Fontaine, X.-M. Liu and C. Diwu, Chem. Geol., 2008, 247, 100-118.

68 M. Bizzarro, A. Simonetti, R. Stevenson and S. Kurszlaukis, Geochim. Cosmochim. Acta, 2003, 67, 289-302.

69 M. Resano, M. Aramendía, L. Rello, M. L. Calvo, S. Bérail and C. Pécheyran, J. Anal. At. Spectrom., 2013, 28, 98-106.

70 X.-Y. Zheng, B. L. Beard, S. Lee, T. R. Reddy, H. Xu and C. M. Johnson, Chem. Geol., 2017, 235-247.

71 W. Zhang, Z. Hu, D. Günther, Y. Liu, W. Ling, K. Zong, H. Chen and S. Gao, Anal. Chim. Acta, 2016, 948, 9-18.

72 M. R. Van Acker, A. Shahar, E. D. Young and M. L. Coleman, Anal. Chem., 2006, 78, 4663-4667.

73 S. P. Sylva, L. Ball, R. K. Nelson and C. M. Reddy, Rapid Commun. Mass Spectrom., 2007, 21, 3301-3305.

74 A. Amrani, A. L. Sessions and J. F. Adkins, Anal. Chem., 2009, 81, 9027-9034.

75 V. N. Epov, P. Rodriguez-Gonzalez, J. E. Sonke, E. Tessier, D. Amouroux, L. M. Bourgoin and O. F. Donard, Anal. Chem., 2008, 80, 3530-3538.

76 P. Rodríguez-González, V. N. Epov, C. Pecheyran, D. Amouroux and O. F. Donard, Mass Spectrom. Rev., 2012, 31, 504-521.

77 A. J. Wall, R. C. Capo, B. W. Stewart, T. T. Phan, J. C. Jain, J. A. Hakala and G. D. Guthrie, J. Anal. At. Spectrom., 2013, 28, 1338-1344.

78 J. E. Sonke, T. Zambardi and J.-P. Toutain, J. Anal. At. Spectrom., 2008, 23, 569-573.

79 L. E. Gratz, G. J. Keeler, J. D. Blum and L. S. Sherman, Environ. Sci. Technol., 2010, 44, 7764-7770.

80 L. S. Sherman, J. D. Blum, G. J. Keeler, J. D. Demers and J. T. Dvonch, Environ. Sci. Technol., 2011, 46, 382-390.

81 J. D. Demers, J. D. Blum and D. R. Zak, Global Biogeochem. Cycles, 2013, 27, 222-238.

82 H. Lin, D. Yuan, B. Lu, S. Huang, L. Sun, F. Zhang and Y. Gao, J. Anal. At. Spectrom., 2015, 30, 353-359.

83 X. Fu, L.-E. Heimbürger and J. E. Sonke, J. Anal. At. Spectrom., 2014, 29, 841-852.

84 L. Yang, E. Dabek-Zlotorzynska and V. Celo, J. Anal. At. Spectrom., 2009, 24, 1564-1569.

85 W. Russell, D. Papanastassiou and T. Tombrello, Geochim. Cosmochim. Acta, 1978, 42, 1075-1090.

86 J. D. Blum and M. W. Johnson, Rev. Mineral. Geochem., 2017, 82, 733-757.

87 S.-S. Sun and W. F. McDonough, Geol. Soc. London, Spec. Publ., 1989, 42, 313-345.

88 H. Balsiger, J. Geiss and M. E. Lipschutz, Earth Planet. Sci. Lett., 1969, 6, 117-122.

89 I. Z. Pelly, M. E. Lipschutz and H. Balsiger, Geochim. Cosmochim. Acta, 1970, 34, 1033-1036. 
90 J. Prytulak, S. G. Nielsen and A. N. Halliday, Geostand. Geoanal. Res., 2011, 35, 307-318.

91 F. Wu, Y. Qi, H. Yu, S. Tian, Z. Hou and F. Huang, Chem. Geol., 2016, 421, 17-25.

92 S. Schuth, I. Horn, A. Brüske, P. E. Wolff and S. Weyer, Ore Geol. Rev., 2017, 81, 1271-1286.

93 J. Prytulak, S. G. Nielsen, D. A. Ionov, A. N. Halliday, J. Harvey, K. A. Kelley, Y. L. Niu, D. W. Peate, K. Shimizu and K. W. W. Sims, Earth Planet. Sci. Lett., 2013, 365, 177189.

94 O. Barndorff-Nielsen, Information and Exponential Families in Statistical Theory, John Wiley, 2014.

95 F. Wu, T. Qin, X. Li, Y. Liu, J.-H. Huang, Z. Wu and F. Huang, Earth Planet. Sci. Lett., 2015, 426, 216-224.

96 G. T. Ventura, L. Gall, C. Siebert, J. Prytulak, P. Szatmari, M. Hürlimann and A. N. Halliday, Appl. Geochem., 2015, 59, 104-117.

97 D. Rehder, Metallomics, 2015, 7, 730-742.

98 D. Malinovsky and N. A. Kashulin, Anal. Methods, 2016, 8, 5921-5929.

99 K. von Allmen, M. E. Böttcher, E. Samankassou and T. F. Nägler, Chem. Geol., 2010, 277, 70-77.

100 T. Miyazaki, J.-I. Kimura and Q. Chang, J. Anal. At. Spectrom., 2014, 29, 483-490.

101 X. Nan, F. Wu, Z. Zhang, Z. Hou, F. Huang and H. Yu, J. Anal. At. Spectrom., 2015, 30, 2307-2315.

102 K. Zuilen, T. F. Nägler and T. D. Bullen, Geostand. Geoanal. Res., 2016, 40, 543-558.

103 F. Moynier, E. A. Pringle, A. Bouvier and J. Moureau, Chem. Geol., 2015, 413, 1-6.

104 K. van Zuilen, T. Müller, T. F. Nägler, M. Dietzel and T. Küsters, Geochim. Cosmochim. Acta, 2016, 186, 226-241.

105 V. Mavromatis, K. van Zuilen, B. Purgstaller, A. Baldermann, T. F. Nägler and M. Dietzel, Geochim. Cosmochim. Acta, 2016, 190, 72-84.

106 C. Pretet, K. Zuilen, T. F. Nägler, S. Reynaud, M. E. Böttcher and E. Samankassou, Depositional Record, 2015, 1, 118-129.

107 T. Bullen and O. Chadwick, Chem. Geol., 2016, 422, 25-45.

108 Z. Cao, C. Siebert, E. C. Hathorne, M. Dai and M. Frank, Earth Planet. Sci. Lett., 2016, 434, 1-9.

109 T. J. Horner, C. W. Kinsley and S. G. Nielsen, Earth Planet. Sci. Lett., 2015, 430, 511-522.

110 S. L. Bates, K. R. Hendry, H. V. Pryer, C. W. Kinsley, K. M. Pyle, E. M. S. Woodward and T. J. Horner, Geochim. Cosmochim. Acta, 2017, 204, 286-299.

111 Y.-T. Hsieh and G. M. Henderson, Earth Planet. Sci. Lett., 2017, 473, 269-278.

112 W. Li, B. L. Beard and S. Li, J. Anal. At. Spectrom., 2016, 31, 1023-1029.

113 K. Wang and S. B. Jacobsen, Geochim. Cosmochim. Acta, 2016, 178, 223-232.

114 S. J. Jiang, R. S. Houk and M. A. Stevens, Anal. Chem., 1988, 1217-1221.

115 I. Feldmann, N. Jakubowski and D. Stuewer, Fresenius' J. Anal. Chem., 1999, 365, 415-421.

116 I. Feldmann, N. Jakubowski, C. Thomas and D. Stuewer, Fresenius' J. Anal. Chem., 1999, 365, 422-428.
117 I. C. Bourg, F. M. Richter, J. N. Christensen and G. Sposito, Geochim. Cosmochim. Acta, 2010, 74, 2249-2256.

118 F. M. Richter, E. Bruce Watson, M. Chaussidon, R. Mendybaev, J. N. Christensen and L. Qiu, Geochim. Cosmochim. Acta, 2014, 138, 136-145.

119 K. Wang and S. B. Jacobsen, Nature, 2016, 538, 487-490.

120 C. A. Parendo, S. B. Jacobsen and K. Wang, Proc. Natl. Acad. Sci. U. S. A., 2017, 114, 1827-1831.

121 W. Li, Acta Geochim., 2017, DOI: 10.1007/s11631-017-01671.

122 M. Berglund and M. E. Wieser, Pure Appl. Chem., 2011, 83, 397-410.

123 J. Creech, J. Baker, M. Handler, M. Schiller and M. Bizzarro, J. Anal. At. Spectrom., 2013, 28, 853-865.

124 J. Roberts and A. Thomson, Prog. Nucleic Acid Res. Mol. Biol., 1979, 22, 71-133.

125 M. J. Abrams and B. A. Murrer, Science, 1993, 261, 725.

126 Z. Guo and P. J. Sadler, Adv. Inorg. Chem., 1999, 49, 183-306.

127 Y. P. Ho, S. C. Au-Yeung and K. K. To, Med. Res. Rev., 2003, 23, 633-655.

128 R. M. Heck, R. J. Farrauto and S. T. Gulati, Catalytic Air Pollution Control: Commercial Technology, John Wiley, 2009.

129 J. Kašpar, P. Fornasiero and N. Hickey, Catal. Today, 2003, 77, 419-449.

130 K. H. Ek, G. M. Morrison and S. Rauch, Sci. Total Environ., 2004, 334, 21-38.

131 J. C. Ely, C. R. Neal, C. F. Kulpa, M. A. Schneegurt, J. A. Seidler and J. C. Jain, Environ. Sci. Technol., 2001, 35, 3816-3822.

132 F. White, T. Collins and F. Rourke, Phys. Rev., 1956, 101, 1786-1791.

133 T. B. Coplen, Pure Appl. Chem., 1996, 68, 2339-2359.

134 C. S. Briche, P. D. Taylor and P. De Bièvre, Anal. Chem., 1997, 69, 791-793.

135 K. Hattori, D. P. Menagh and T. J. S. Cole, Anal. Chem., 1998, 70, 4100-4103.

136 C. W. Briche, A. Held, M. Berglund, P. De Bièvre and P. Taylor, Anal. Chim. Acta, 2002, 460, 41-47.

137 H. Emteborg, X. Tian, M. Ostermann, M. Berglund and F. C. Adams, J. Anal. At. Spectrom., 2000, 15, 239-246.

138 H. Emteborg, X. Tian and F. C. Adams, J. Anal. At. Spectrom., 1999, 14, 1567-1572.

139 T. S. Kruijer, M. Fischer-Gödde, T. Kleine, P. Sprung, I. Leya and R. Wieler, Earth Planet. Sci. Lett., 2013, 361, 162-172.

140 N. Wittig, M. Humayun, A. Brandon, S. Huang and I. Leya, Earth Planet. Sci. Lett., 2013, 361, 152-161.

141 J. B. Creech, J. A. Baker, M. R. Handler and M. Bizzarro, Chem. Geol., 2014, 363, 293-300.

142 S. Rauch, H. F. Hemond, C. Barbante, M. Owari, G. M. Morrison, B. Peucker-Ehrenbrink and U. Wass, Environ. Sci. Technol., 2005, 39, 8156-8162.

143 G. C. Koltsakis and A. M. Stamatelos, Prog. Energy Combust. Sci., 1997, 23, 1-39.

144 K. E. Jarvis, S. J. Parry and J. M. Piper, Environ. Sci. Technol., 2001, 35, 1031-1036.

145 M. Müller and K. G. Heumann, Fresenius' J. Anal. Chem., 2000, 368, 109-115. 
146 J. Schäfer, J.-D. Eckhardt, Z. A. Berner and D. Stüben, Environ. Sci. Technol., 1999, 33, 3166-3170.

147 A. Limbeck, J. Rendl, G. Heimburger, A. Kranabetter and H. Puxbaum, Atmos. Environ., 2004, 38, 1979-1987.

148 B. Mayer, N. Wittig, M. Humayun and I. Leya, Astrophys. J., 2015, 809, 180.

149 M. Rehkämper and A. N. Halliday, Talanta, 1997, 44, 663672.

150 M. Ek, A. C. Hunt and M. Schönbächler, J. Anal. At. Spectrom., 2017, 32, 647-656.

151 J. Creech, F. Moynier and M. Bizzarro, Geochim. Cosmochim. Acta, 2017, DOI: 10.1016/j.gca.2017.04.040.

152 T. Fujii, F. Moynier, A. Agranier, E. Ponzevera and M. Abe, Proceedings Radiochimica Acta, 2011, 1, 339-344.

153 A. V. Chugaev and I. V. Chernyshev, Geochem. Int., 2012, 50, 899-910.

154 N. C. Mueller and B. Nowack, Environ. Sci. Technol., 2008, 42, 4447-4453.

155 Y. Wu, Q. Zhou, H. Li, W. Liu, T. Wang and G. Jiang, Aquat. Toxicol., 2010, 100, 160-167.

156 D. Lu, Q. Liu, T. Zhang, Y. Cai, Y. Yin and G. Jiang, Nat. Nanotechnol., 2016, 11, 682-686.

157 B. Park, P. Martin, C. Harris, R. Guest, A. Whittingham, P. Jenkinson and J. Handley, Part. Fibre Toxicol., 2007, 4, 12.

158 K. Savolainen, L. Pylkkänen, H. Norppa, G. Falck, H. Lindberg, T. Tuomi, M. Vippola, H. Alenius, K. Hämeri, J. Koivisto, D. Brouwer, D. Mark, D. Bard, M. Berges, E. Jankowska, M. Posniak, P. Farmer, R. Singh, F. Krombach, P. Bihari, G. Kasper and M. Seipenbusch, Safety Sci., 2010, 48, 957-963.

159 H. Tazoe, H. Obata and T. Gamo, J. Anal. At. Spectrom., 2007, 22, 616-622.

160 R. Nakada, Y. Takahashi and M. Tanimizu, Geochim. Cosmochim. Acta, 2013, 103, 49-62.

161 O. Takeshi and T. Hirata, Anal. Sci., 2013, 29, 47-53.

162 A. Laycock, B. Coles, K. Kreissig and M. Rehkämper, J. Anal. At. Spectrom., 2016, 31, 297-302.

163 K. Yokoi, M. Yakushiji, M. Hatanaka, K. Kubono and T. Koide, Fresenius' J. Anal. Chem., 1999, 365, 364-367.

164 R. Nakada, Y. Takahashi and M. Tanimizu, Geochim. Cosmochim. Acta, 2016, 181, 89-100.

165 T.-L. Chang, M.-T. Zhao, W.-J. Li, J. Wang and Q.-Y. Qian, Int. J. Mass Spectrom., 1998, 177, 131-136.

166 I. T. Platzner, K. Habfast, A. Walder and A. Goetz, Modern Isotope Ratio Mass Spectrometry, Wiley, 1997.

167 E. Albalat, P. Telouk and F. Albarède, Earth Planet. Sci. Lett., 2012, 355-356, 39-50.

168 C. L. De La Rocha, M. A. Brzezinski and M. J. DeNiro, Anal. Chem., 1996, 68, 3746-3750.
169 T. Zambardi and F. Poitrasson, Geostand. Geoanal. Res., 2011, 35, 89-99.

170 R. Georg, B. Reynolds, A. West, K. Burton and A. Halliday, Earth Planet. Sci. Lett., 2007, 261, 476-490.

171 P. A. P. von Strandmann, S. Opfergelt, Y.-J. Lai, B. Sigfússon, S. R. Gislason and K. W. Burton, Earth Planet. Sci. Lett., 2012, 339, 11-23.

172 R. M. Garrels, Am. J. Sci., 1983, 283, 641-683.

173 E. Engström, I. Rodushkin, D. C. Baxter and B. Öhlander, Anal. Chem., 2006, 78, 250-257.

174 E. Engström, I. Rodushkin, J. Ingri, D. C. Baxter, F. Ecke, H. Österlund and B. Öhlander, Chem. Geol., 2010, 271, 142-152.

175 R. Georg, B. Reynolds, M. Frank and A. Halliday, Earth Planet. Sci. Lett., 2006, 249, 290-306.

176 A. Zhang, J. Zhang, R. Zhang and Y. Xue, J. Anal. At. Spectrom., 2014, 29, 2414-2418.

177 A.-Y. Zhang, J. Zhang, R.-F. Zhang and X. Yun, Chin. J. Anal. Chem., 2015, 43, 1353-1359.

178 P. Grasse, M. A. Brzezinski, D. Cardinal, G. F. de Souza, P. Andersson, I. Closset, Z. Cao, M. Dai, C. Ehlert and N. Estrade, J. Anal. At. Spectrom., 2017, 32, 562-578.

179 M. N. Croteau, S. K. Misra, S. N. Luoma and E. ValsamiJones, Environ. Sci. Technol., 2014, 48, 10929-10937.

180 F. R. Khan, A. Laycock, A. Dybowska, F. Larner, B. D. Smith, P. S. Rainbow, S. N. Luoma, M. Rehkamper and E. ValsamiJones, Environ. Sci. Technol., 2013, 47, 8532-8539.

181 Y. Yin, Z. Tan, L. Hu, S. Yu, J. Liu and G. Jiang, Chem. Rev., 2017, 117, 4462-4487.

182 Q. Liu, H. Hintelmann and G. Jiang, Natl. Sci. Rev., 2016, 3, 410.

183 P.-A. Krayenbuehl, T. Walczyk, R. Schoenberg, F. von Blanckenburg and G. Schulthess, Blood, 2005, 105, 38123816.

184 S. Smith, T. McCoy, D. Gazda, J. Morgan, M. Heer and S. Zwart, Nutrients, 2012, 4, 2047-2068.

185 V. Balter, A. Nogueira da Costa, V. P. Bondanese, K. Jaouen, A. Lamboux, S. Sangrajrang, N. Vincent, F. Fourel, P. Télouk, M. Gigou, C. Lécuyer, P. Srivatanakul, C. Bréchot, F. Albarède and P. Hainaut, Proc. Natl. Acad. Sci. U. S. A., 2015, 112, 982-985.

186 J. F. Ma, K. Tamai, N. Yamaji, N. Mitani, S. Konishi, M. Katsuhara, M. Ishiguro, Y. Murata and M. Yano, Nature, 2006, 440, 688-691.

187 Y. Sun, L. Wu, X. Li, L. Sun, J. Gao and T. Ding, J. Geophys. Res.: Biogeosci., 2016, 121, 2829-2841.

188 B. Balmer, R. L. Bernays, S. S. Kollias and Y. Yonekawa, J. Pediatr. Surg., 2002, 37, 668-672.

189 W. Daum and A. Winkel, Navigation of medical instrument, US Pat., US20040064148, 2006. 